\title{
1 Comparative Life Cycle Assessment of Fossil and Bio-based Polyethylene \\ 2 Terephthalate (PET) Bottles
}

4 Luyi Chen ${ }^{1,2}$, Rylie E.O. Pelton ${ }^{1,2}$ and Timothy M. Smith ${ }^{1,2}$

6 Luyi Chen

7 chen3461@umn.edu

$9{ }^{1}$ NorthStar Initiative for Sustainable Enterprise, Institute on the Environment, 325 Learning and Environmental

10 Sciences, 1954 Buford Ave, St. Paul, MN 55108

112 Department of Bioproducts and Biosystems Engineering, University of Minnesota Twin Cities, 1390 Eckles Ave.,

12 Saint Paul, MN 55108

\section{Abstract}

15 Both biofuels and bioplastics are often regarded as sustainable solutions to current environmental problems

16 such as climate change, fossil depletion and acidification. However, both have been criticized for being

17 economically costly, competing with other societally beneficial goods such as food, and offering limited

18 environmental benefits compared to their fossil counterparts. This study provides a comparative

19 environmental Life Cycle Analysis (LCA) for 100\% bio-based polyethylene terephthalate (PET) bottles,

20 versus fully fossil-based and partially bio-based PET bottles. An attributional life cycle assessment (aLCA)

21 and sensitivity analysis of key assumptions is carried out to compare cradle-to-factory-gate impacts (i.e.

22 feedstock extraction, component production and product manufacturing) of twelve PET bottle production

23 scenarios. Results indicate that woody-biomass based PET bottles have $21 \%$ less global warming potential

24 and require $22 \%$ less fossil fuel than their fossil based counterparts, but perform worse in other categories

(C) 2016. This manuscript version is made available under the Elsevier user license http://www.elsevier.com/open-access/userlicense/1.0/ 
25 such as ecotoxicity and ozone depletion impacts. Results are sensitive to impact allocation assumptions as 26 well as parameter input assumptions related to isobutanol production. In most categories, with avoided 27 impact credits considered, forest residue feedstocks result in overall better environmental performance than 28 corn stover feedstocks for bio-PET bottle production. The variability in avoided burdens could alter the 29 relative environmental rankings for fossil and bio-PET bottles. Depending on the biomass feedstock,

30 extraction and pre-processing are likely more emission-intensive than the corresponding fossil refinery 31 processes due to the significant upstream emissions embodied in the application of fertilizers, and the 32 significant chemical and energy inputs required to break recalcitrant lignocellulosic bonds.

34 Keywords Comparative Life Cycle Assessment (LCA); Polyethylene Terephthalate (PET); Paraxylene 35 (PX); Bioplastics; Bio-Polyethylene Terephthalate (Bio-PET) Bottle.

\section{Introduction}

39 In response to growing concerns about climate change, many countries have enacted stringent carbon

40 policies to limit greenhouse gas emissions of domestic industries. As a result, growth of traditional fossil

41 refineries and fossil power facilities, which together generate the leading share of total carbon emissions,

42 has slowed. However, global demand of energy supplies will continue to grow, with a $37 \%$ increase by

432040 (USEIA, 2013). Consequently, there is an urgent need to identify and utilize renewable resources to

44 meet this increasing demand. Biomass is recognized as a sustainable alternative due to its abundant

45 availability, carbon-neutrality and low sulfur content. Countries like the United States, India, China, South

46 Africa, and those in the European Union have all set ambitious goals to achieve a higher share of biofuels

47 in their overall fuel mix (Vivekanandhan et al., 2013). Nonetheless, the commercialized first generation

48 biofuels have been criticized for competing with food crops (Pimentel et al., 2008; Sims et al., 2010),

49 causing considerable environmental impacts during biomass farming (Valipour; 2015a; Valipour, 2015b)

50 and having limited greenhouse gas emission reductions (De Fraiture et al., 2008; Fargione et al., 2008; 
51 Melillo et al., 2009; Zaimes et al., 2013). To address those issues, second generation biofuels have been 52 developed primarily from non-food crops, agricultural wastes, and forest residues (Hsu et al., 2010), 53 although the high cost of processing enzymes and building new facilities currently hinders their 54 commercialization (Stephen et al., 2012). So far, government subsidies are the primary force propelling 55 biomass resource utilization (Vivekanandhan et al., 2013), but these are temporary and can be decreased or 56 even suspended if no further economic benefits are generated with biofuels (USEIA, 2013).

58 A promising solution to the problem is establishing integrated biorefineries, where biochemicals and 59 biomaterials are coproduced with biofuels. This is inspired by fossil fuel refineries, where less than $10 \%$ of

60 fossil oil is used to produce non-energy products, but it accounts for nearly half of the total economic value 61 of the whole petroleum refinery system (Hatti-Kaul, 2010; Nelson and Powell, 2010). Biochemicals and 62 biomaterials have similar potential to reduce the per unit operation costs of biofuel production and to better 63 utilize biomass feedstocks (Bergeron et al., 2012; Cherubini, 2010; Fernando et al., 2006; Kamm et al., 64 2008; Kelloway and Daoutidis, 2013). Unfortunately, biomaterials receive much less attention than their 65 biofuel counterparts. Challenges arise from a scarcity of data on the not-yet-industrialized biomass 66 conversion process, as well as issues related to the allocation of environmental impacts or costs between 67 different co-products. Such uncertainty might lead to diverse or even completely reverse results (Shen et

68 al., 2012; Spatari et al., 2005; Tabone et al., 2010; Williams et al., 2009). Furthermore, the pool of potential

69 biochemicals and biomaterials is vast, making it difficult to identify the best candidate to maximize profits 70 and minimize emissions.

72 As public awareness of sustainable packaging has grown, the possibilities of bioplastics has emerged as a 73 potential alternative to petro-based plastics. Though currently occupying a trivial share of the plastics 74 market (less than 1\%), worldwide bioplastics production has been forecast to spike starting in 2018 75 (Scharathow, 2012). The term "bioplastics" implies either that the polymer is generated from renewable 76 resources, or that the plastic is biodegradable or compostable at the end-of-life (Gironi and Piemonte, 77 2011). At first, scholars targeted biodegradable bio-based polymers such as Polylactic Acid (PLA), 
78 claiming that they were more environmentally friendly than petro-plastics (Shen et al., 2012; Vink et al.,

79 2003). However, market expansion of those materials is limited by their low-barrier properties (Harada et

80 al., 2007; Jamshidian et al., 2010), and has therefore triggered an interest in strong, non-biodegradable

81 bioplastics such as bio-PET. PET is widely used in construction, transportation, packaging and engineering.

82 In 2007, global PET production reached 46 million metric tons, taking $15 \%$ of the worldwide synthetic

83 polymer production capacity (Shen et al., 2012). The United States consumes the largest portion of the PET

84 market, with $9.5 \mathrm{~kg}$ PET per capita use in 2011 (Koncept Analytics, 2013).

86 Despite its popularity, only a few efforts have been made to analyze the life cycle impacts of producing 87 bio-based PET materials, and they mostly focus on partially bio-based PET, where only one of the two 88 precursors, ethylene glycol (EG), is produced from biomass; the other precursor, purified terephthalic acid 89 (PTA), due to technical constraints, remains fossil based (Shen et al., 2012; Tabone et al., 2010). To 90 remedy this exclusion, our study presents a novel manufacturing process to produce both partially and fully 91 bio-PET bottles using lignocellulosic biomass from forest residues. The abundance of available forest 92 residues allows us to extract energy from biomass without competing with food farming (Gan and Smith, 93 2007; Repo et al., 2012). After using an integrated method to convert forest residues to isobutanol (IBA) 94 (Feldman et al., 2011), the IBA can be processed into paraxylene (PX) (Peters et al., 2010), a key 95 prerequisite for PTA production, or processed into biofuels, although the current study will focus on the 96 former pathway. The Coca-Cola Company plans to use woody biomass-based PTA to produce 100\% bio97 based PET beverage bottles (citation), suggesting the timely nature of this study. The aim of this study is to 98 conduct a comparative Life Cycle Assessment (LCA) for the traditional petroleum-based PET bottles and 99 bio-based PET bottles. Results of the study will provide an important reference to policy makers, bio100 plastic researchers, industry partners and purchasers, and will contribute to the optimization of integrated 101 biorefinery system design.

102 
105 2.1 Attributional Life Cycle Assessment (aLCA) Model

106

107 This study applied the Life Cycle Assessment (LCA) methodology, which is used for the estimation and

108 evaluation of environmental impacts attributable to the life cycle of a product (Rebitzer et al., 2004). It

109 encompasses the material and energy flows within the system boundary and calculates relevant impacts

110 generated by each unit process, such as greenhouse gas emissions, toxic impacts to an ecosystem, water

111 contamination, and so forth (Bare et al., 2012). The LCA model was established through the thinkstep GaBi

112 software (GaBi, 2014), complying with ISO 14040 and 14044 standards (ISO, 2006). Considering the data

113 availability of pilot and demonstration biorefinery facilities, a traditional attributional life cycle assessment

114 (aLCA) model was applied with sensitivity analysis of key assumptions in the system. Based on this initial

115 report, future research could focus on developing consequential LCA models.

116

1172.2 Goal, Scope, System Boundary and Functional Unit (FU) of the Study

119 The goal of this study is to quantify and compare environmental impacts of PET bottles produced through

120 traditional petroleum refineries and through biorefineries in the context of the United States. The aim of

121 including various feedstock options is also to explore the system-wide advantages or limitations of fully

122 bio-based PET bottle production scenarios over partially bio-based and fossil-derived PET bottles.

124 A cradle-to-factory-gate approach was applied in this paper, given that the upstream processes (feedstock

125 extraction, component production and product manufacturing) of PET bottle life cycles are what primarily

126 differentiates bio-based PET from fossil PET. The consumer use phase and the end-of-life phase (disposal

127 or recycling) are excluded from the analysis, given the complexity of possible options available to

128 adequately handle bioplastics in the current waste streams and that consumer use impacts will be identical 
129 between scenarios (Komly et al., 2012; Shen et al., 2011; Zhang and Wen, 2013); however, end-of-life

130 impacts are worth further exploration in future work.

131

132 Regarding the production of PET bottles, the two chemical precursors, PTA and EG, are synthesized

133 separately. In the traditional production of PET, both PTA and EG were fossil refinery products. Petroleum

134 refiners first separate out PX from a xylene mixture and then oxidize it to PTA. Similarly, ethylene

135 produced from the alkene co-products of natural gas production are processed through hydration and

136 oxidation to produce EG. These two precursors are then polymerized to amorphous-grade PET granulate,

137 which is then turned into bottle grade granulate through solid-state polycondensation processes. Finally,

138 PET bottles are shaped through injection blow molding. For partially bio-based PET bottles (30\% or 70\%),

139 one of the two fossil precursors is substituted with a bio-based material; for fully bio-based PET bottles,

140 both are produced from biomass. The processing of bio-PTA and bio-EG into PET bottles is identical to the

141 processes described for petro-PET. Bio-based versions of PTA and EG can be produced from a variety of

142 biomass materials, the environmental impacts of which are explored in different scenarios (see 'Scenario

143 Description'). Fig. 1 illustrates the process flow diagrams for producing fully bio-based PET bottles, which

144 represents the system boundary of the study.

145 For the functional unit (FU), the environmental impact per $1 \mathrm{~kg}$ of PET bottles was investigated. This

146 equals the weight of approximately 100 bottles with 0.5 -liter capacity, and is kept consistent for all

147 compared scenarios in order to yield meaningful comparative results (Curran, 1996; NAPCOR, 2016). 


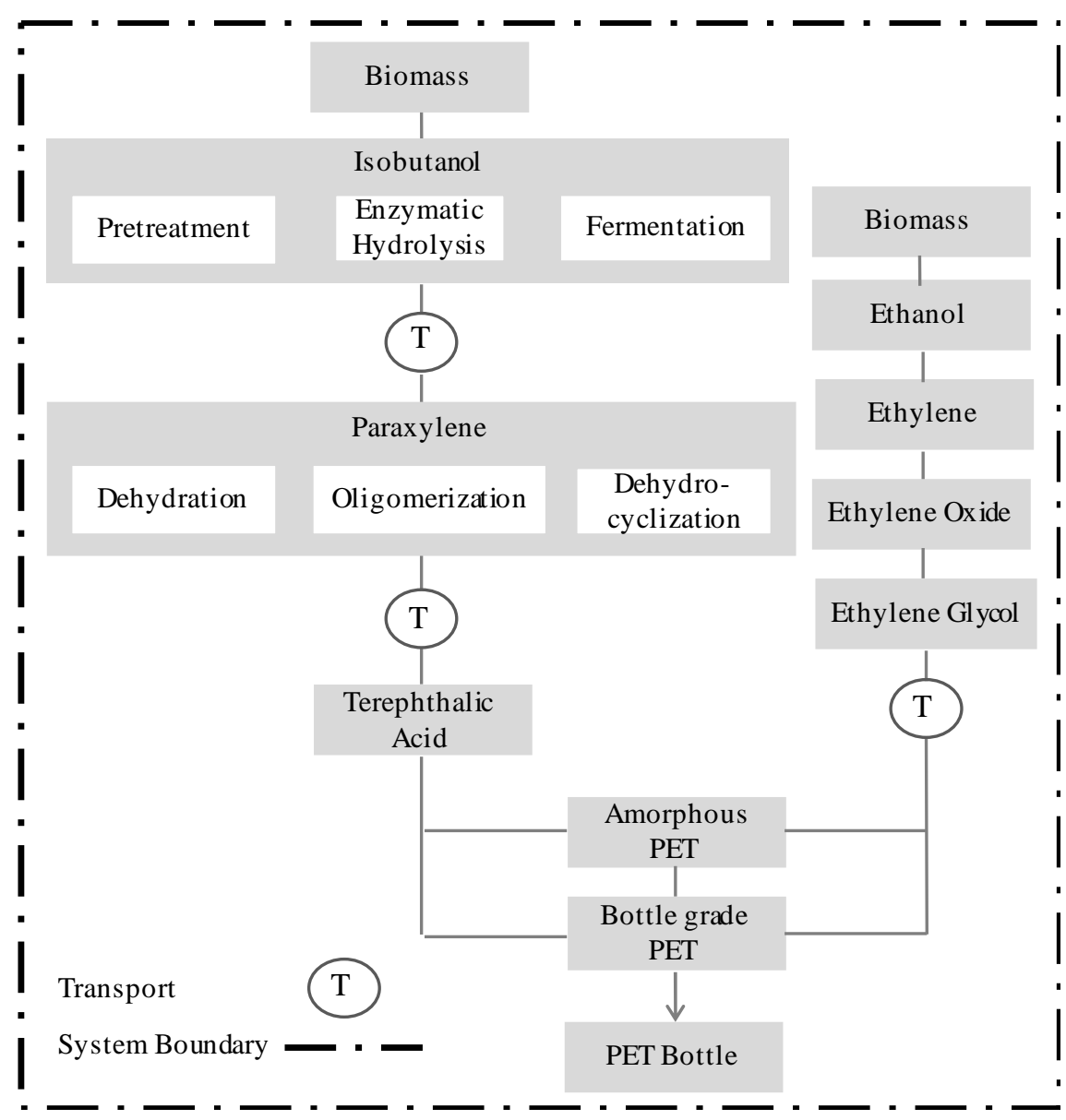

149 Fig. 1. Cradle-to-Gate system boundary for 100\% bio-based PET bottles. Grey boxes represent the product 150 output flow of each intermediate production process. White boxes indicate the more detailed account of the 151 novel wood-based isobutanol and paraxylene production processes and life cycle inventories that are a 152 primary focus in this study.

\subsection{Life Cycle Inventory (LCI)}

156 Life cycle models were developed in the thinkstep GaBi software (GaBi, 2014), and Ecoinvent (Weidema

157 et al., 2013) was the primary database applied in this study, with supplementary information retrieved from

158 literature (Hsu et al., 2010; Tao et al., 2014), PlasticsEurope database (PlasticsEurope, 2013) and the U.S.

159 Life Cycle Inventory database (NREL, 2012). Datasets established on a European industry background

160 were altered to fit the context of the U.S. industry. For biomass-derived PX production, each process was

161 developed individually based on proprietary information provided by industry collaborators as well as 
162 published literatures. Detailed assumptions and dataset descriptions are documented in the Supporting

163 Information (SI) of this study.

164

165 2.4 Scenario Description

166

167 PTA accounts for approximately $70 \%$ of the weight of PET resin, while EG contributes to the rest (PE

168 INTERNATIONAL AG., 2014). PET bottles with bio-based EG and fossil-based PTA are therefore

169 referred to as $30 \%$ bio-based bottles; these are already available on the market, as in the Dasani water

170 bottles from the Coca-Cola Company. Currently the bio-EG used for Dasani bottles is manufactured in

171 Indonesia, and the company seeks to begin producing bio-PTA in order to be a leader in producing $100 \%$

172 bio-based PET bottles (Schut, 2012). Although no real 'bio-PTA + fossil EG' scenarios have been proposed

173 for commercialization, these scenarios were nonetheless included in this study (Scenario 5 and Scenario 9)

174 for comparison purposes. Bio-based EG is processed from biomass-derived ethanol, which has life cycle

175 inventory data available from a variety of feedstocks. In this study, corn, switchgrass and wheat straw were

176 considered as raw materials of bio-EG, while corn stover and forest residues were selected as feedstock for

177 bio-PTA. Together with fossil- based PTA and EG, 12 PET bottle production scenarios were established, as

178 shown in Table 1.

179

180 Table 1

181 Scenarios of Fossil-based and Bio-based PET Bottles

\begin{tabular}{llllllll}
\hline Scenario & $\begin{array}{l}\text { Feedstock } \\
\text { of PTA }\end{array}$ & $\begin{array}{l}\text { Feedstock } \\
\text { of EG }\end{array}$ & $\begin{array}{l}\% \text { of } \\
\text { Biomass }\end{array}$ & $\begin{array}{l}\text { Scenario } \\
\text { Feedstock } \\
\text { of PTA }\end{array}$ & $\begin{array}{l}\text { Feedstock } \\
\text { of EG }\end{array}$ & $\begin{array}{l}\% \text { of } \\
\text { Biomass }\end{array}$ \\
\hline $1^{\text {a }}$ & Fossil & Fossil & 0 & 7 & Wood & Switchgrass & 100 \\
2 & Fossil & Corn & 30 & 8 & Wood & Wheat Straw & 100 \\
3 & Fossil & Switchgrass & 30 & 9 & Corn Stover & Fossil & 70 \\
4 & Fossil & Wheat Straw & 30 & 10 & Corn Stover & Corn & 100
\end{tabular}




\begin{tabular}{llllllll}
5 & Wood & Fossil & 70 & 11 & Corn Stover & Switchgrass & 100 \\
6 & Wood & Corn & 100 & 12 & Corn Stover & Wheat Straw & 100 \\
\hline
\end{tabular}

$182{ }^{\mathrm{a}}$ Baseline scenario.

\section{2.4.1 Forest Residues}

186 Every year, the amount of solar energy stored by plants is about 10 times greater than the total amount of

187 worldwide energy used by humans. About 13 billion metric tons (dry weight) of wood are produced

188 annually, providing an abundant material resource for renewable energy (Kumar et al., 2008). Much of this

189 material is harvested for wood-based products production. However, harvesting operations currently collect

190 only $60 \%$ of above-ground forest biomass, leaving the remainder as residues. Typically, harvest residues

191 are either collected and burned, or left to decompose on the forest floor (Ganguly et al., 2014). Replacing

192 fossil fuels with biofuels derived from forest residues could help to mitigate climate change (Gan and

193 Smith, 2007; Repo et al., 2012). Removal of extra forest residues also helps reduce fire hazards and

194 improve forest health (Perlack et al., 2011) without threatening industrial wood supplies or contributing to

195 deforestation (Smeets and Faaij, 2007). Douglas fir softwood forest residues from the Pacific Northwest

196 region of the United States were chosen as the source of the raw material for the bio-refinery. Fuel demand

197 for forest regeneration, thinning and harvesting operations were summarized by Puettmann et al. (2012).

198 We used forest inputs representing the weighted average management intensity, which is characterized by

199 three forest management scenarios (high, medium and low intensity). Upon harvesting, the woody biomass

200 transportation scenario for equipment and distances, as described by Ganguly et al. (2014), were accounted

201 for and documented in the SI. 
205 For a multi-output system, the main problem of LCA lies in how to allocate material and energy flows

206 between primary products and co-products, as well as how to attribute environmental debits or credits

207 among them. According to ISO 14040 and 14044 standards, allocation should be avoided either by dividing

208 the multifunction process into separate subsystems and collecting data for these sub-processes individually,

209 or by expanding the investigated system boundary to include an alternative production system of exported

210 functions (ISO, 2006). The displacement/substitution method was developed based on the concept of

211 system expansion, where the impacts associated with the alternative production of exported functions were

212 subtracted from the investigated system to determine the potential avoided burdens (Guinée, 2002; Tillman,

213 1994; Wang et al., 2011). In the biomass processing scenarios considered in this study, four kinds of

214 avoided impacts were accounted for, with further details recorded in the SI.

215 a. Avoided impacts from slash pile burning (for forest residues). Note that in the Pacific Northwest, to

216 reduce the risk of wildfire, non-merchantable harvesting residues are collected and burned to ashes,

217 thereby increasing emissions due to incomplete combustion (Ganguly et al., 2014; Stevens and Verhé,

218 2004). When bioenergy was harvested from residues, the avoided impacts from slash pile burning were

219 credited to the biofuel production system (Ganguly et al., 2014) and thus subtracted from the emissions

220 of the investigated bio-PET bottle system.

221 b. Avoided impacts from fossil-based steam and electricity production. In the bio-PET bottle production

222 system scenarios, energy supplies were assumed to be internally fulfilled by co-producing energy from

223 a combined heat and power biomass boiler/generator utilizing fermented lignin residues. It was also

224 assumed that any excess electricity produced would be sold back to the grid to displace an equivalent

225 amount of U.S. average electricity supply. Impacts generated by fossil-derived energy production were

226 thereby avoided and subtracted from bio-PET bottle systems.

227 c. Avoided impacts from non-energy co-products (for corn feedstocks). Corn grain, soybean meal and

228 urea are the products considered in this study that are displaced with co-products produced from the

229 advanced dry mill corn ethanol production system (Hsu et al., 2010).

230 d. Carbon storage credits for biomass derived bottles. As bio-PET bottles are chemically equivalent to

231 their fossil counterparts, they will be used and recycled in the same way, and hence the emissions 
associated with these downstream processes will be the same. The carbon in the bio-PET bottles used

233 to be a part of the natural carbon cycle. Now, they are sequestered from the atmosphere in a recyclable

234 plastic product. Therefore, although the end-of-life stage is not included in the scope of this analysis,

235 we find it reasonable to include sequestered biogenic carbon as a credit to bio-PET bottle scenarios

236 (Narayan, 2011; Roberts et al., 2010).

237 When it is not possible to avoid allocation, impacts need to be assigned to different product flows based on

238 physical relationships and corresponding functions (ISO, 2006). Usually, impacts will be allocated based

239 on mass, energy content or economic values. In this study, mass allocation was applied on the forest

240 resource extraction phase, as is recommended in Jungmeier et al 2002 for increased consistency in results.

241 as the primary product of the system was used as a chemical material, not an energy product, and no market

242 value was assigned to the $100 \%$ bio-PET bottles yet. Approximately $39 \%$ of impacts generated during

243 timber production were allocated to residues (Ganguly et al., 2014). Impacts from the woody biomass

244 boiler were allocated to the IBA and PX processes based on the amount of steam and electricity required

245 for each process. Economic allocation could be evaluated in future studies.

\subsubsection{Transport Adjustment}

249 Transport associated with the various inputs for industrial processes was included in life cycle inventory

250 databases. For some inputs, however, modifications were made to reflect particular assumptions. For

251 example, to lower costs and emissions caused by bulky wood delivery, a woody biomass-based IBA

252 processing facility was assumed to be located near softwood harvesting sites in Oregon (Leu et al., 2013).

253 Pilot plants for PX manufacturing are located in the southern U.S., from where they would transport

254 crystallized PX products to Coca-Cola's largest bottling facility, Coca-Cola Bottling Co. Consolidated

255 (CCBCC), in Charlotte, North Carolina (CCBCC, 2016). CCBCC is responsible for manufacturing PTA

256 from PX and producing PET bottles from PTA and EG. With regard to EG, Iowa was selected as the 
257 location that corn, switchgrass, and wheat are planted, harvested and processed into EG. Detailed

258 documentation for transport assumptions is provided in the SI.

2603 Results and Discussion

\section{3.1 Life Cycle Impact Assessment (LCIA)}

264 Impacts are evaluated at the midpoint instead of at endpoint categories in order to reduce uncertainties,

265 since endpoint impacts are subjected to overall much larger uncertainties (Finnveden et al., 2009; Pawelzik

266 et al., 2013). Eight impact categories were analyzed in this study. Most were calculated based on The Tool

267 for the Reduction and Assessment of Chemical and Other Environmental Impacts (TRACI v2.1), which is

268 designed by the U.S. Environmental Protection Agency and normalized to reflect the context of the U.S.

269 industries (Bare et al., 2012). However, exceptions were made on eutrophication and ozone depletion. Life

270 cycle impact characterization models usually take different approaches with eutrophying impacts for land

271 and water systems. Aquatic eutrophication suffers from weak modeling, whereas terrestrial eutrophication

272 is better characterized using the Accumulate Exceedance model (Hauschild et al., 2011) and was thereby

273 adopted in this study. For ozone depletion, results generated from TRACI v2.1 are significantly different

274 from the ReCiPe v1.08 Hierarchy model, despite both being based on the ozone depletion model from the

275 World Meteorological Organization (WMO). Ultimately, the impact indicator from ReCiPe v1.08 was

276 chosen instead of TRACI v2.1 because ReCiPe offers a more detailed method documentation and addresses

277 uncertainties in the model, whereas TRACI v2.1 only briefly explains how those results are generated (Bare

278 et al., 2012; Zelm, 2009).

280 The comparative LCIA results are illustrated in Fig. 2. Solid color bars refer to impacts without including 281 displacement credits, indicating that in almost all categories, bio-PET bottles (both partial and fully bio- 
282 based ones) have worse performance than their $100 \%$ fossil-based counterparts. However, if avoided 283 impacts are counted (depicted as impact offsets by the hashed sections on bars), bottles made from woody

284 biomass PTA show significant advantage over fossil PTA and corn stover PTA bottles. Fig. 3 gives a more

285 detailed profile of impacts from each unit process along the 12-scenario life cycles, with no avoided

286 impacts included. Each bar refers to the impacts generated from producing PTA and EG for each scenario,

287 and does not include PET bottle manufacturing processes because these processes are identical throughout

288 all scenarios (esterification/polymerization, solid state poly-condensation, and injection stretch blow

289 molding). Each color block indicates the impacts derived from a specific unit process; for example, block

290 'PX' shows emissions from upgrading IBA to PX. 

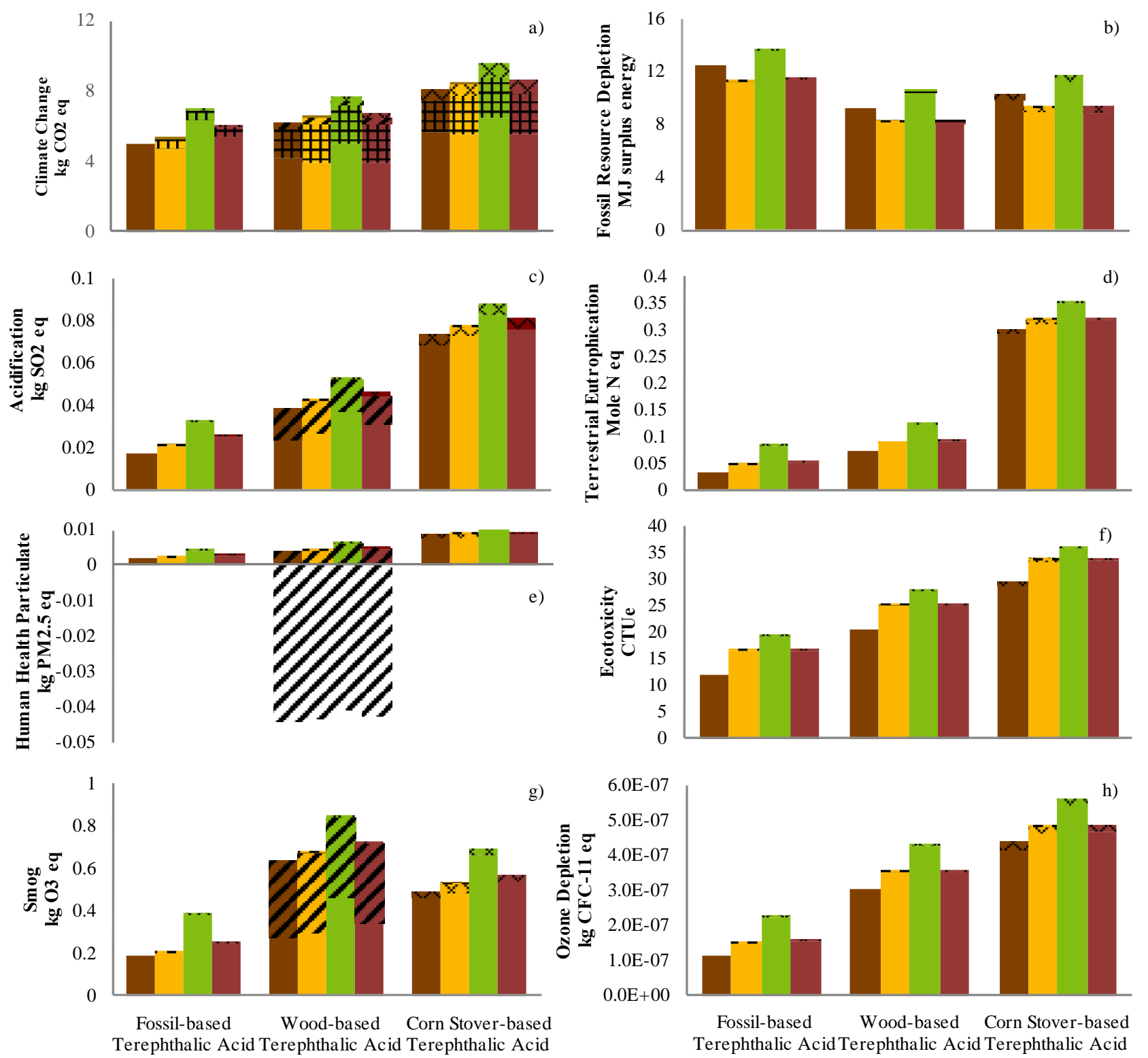

Fossil Ethylene Glycol Corn Ethylene Glycol Switchgrass Ethylene Glycol Wheat Straw Ethylene Glycol Impacts offset from: A voided impacts of slash pile burning (wood) A voided impacts from excess electricity I- Avoided impacts from co-products (com)

\# A voided impact from carbon sequestration in bio-PET

292 Fig. 2. Life Cycle Impact Analysis results for 12 PET bottle production scenarios (per kg PET bottles). 
1 Fossil_Fossil 2 Fossil_Corn 3 Fossil_Switch 4 Fossil Wheat 5 Wood_Fossil 6 Wood_Com 7 Wood_Switch 8 Wood_Wheat

9 Stover_Fossil 10 Stover_Corn 11 Stover_Switch 12 Stover_Wheat

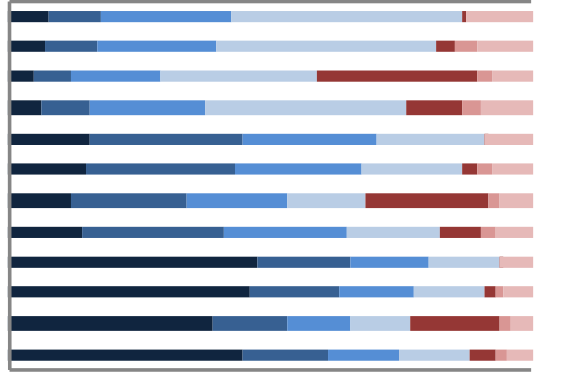

a) Climate Change

$\begin{array}{llllll}0 \% & 20 \% & 40 \% & 60 \% & 80 \% & 100 \%\end{array}$

1 Fossil_Fossil Fossil_Corn 3 Fossil_Switch 4 Fossil_Wheat 5 Wood_Fossil 6 Wood_Corn 7 Wood_Switch 8 Wood_Wheat 9 Stover_Fossil

10 Stover_Corn

11 Stover_Switch

12 Stover_Wheat

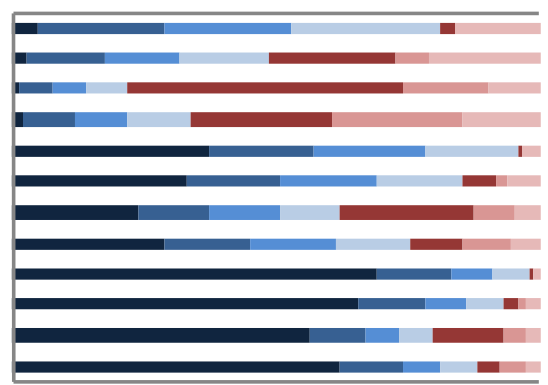

c) Acidification

$\begin{array}{llllll}0 \% & 20 \% & 40 \% & 60 \% & 80 \% & 100 \%\end{array}$

1 Fossil_Fossil

2 Fossil_Corn $\square$

3 Fossil_Switch

4 Fossil_Wheat

5 Wood_Fossil

6 Wood_Corn

7 Wood_Switch

8 Wood_Wheat

9 Stover_Fossil

10 Stover_Corn

1 Stover_Switch

12 Stover_Wheat

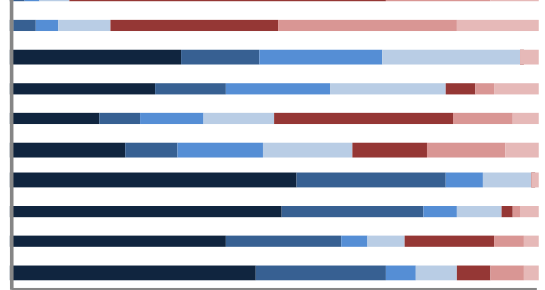

e) Human Health Particulates

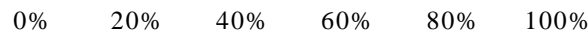

1 Fossil_Fossil

2 Fossil_Corn

3 Fossil_Switch

4 Fossil_Wheat

5 Wood_Fossil

6 Wood_Corn

7 Wood_Switch

8 Wood Wheat

9 Stover_Fossil

10 Stover_Corn

1 Stover_Switch

12 Stover_Wheat

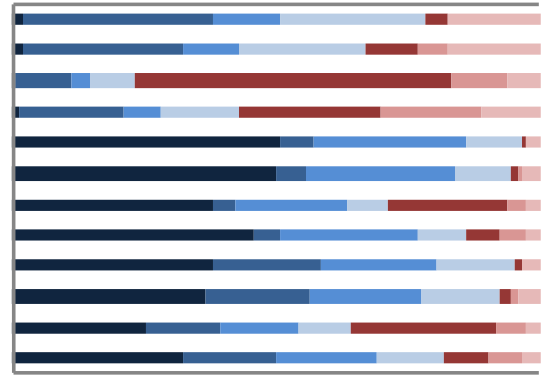

g) Smog

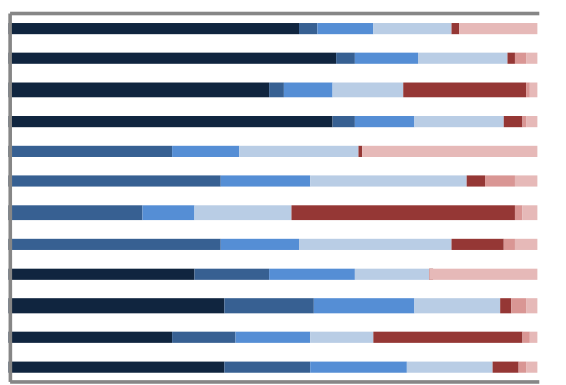

b) Fossil Fuel Depletion

$\begin{array}{llllll}0 \% & 20 \% & 40 \% & 60 \% & 80 \% & 100 \%\end{array}$

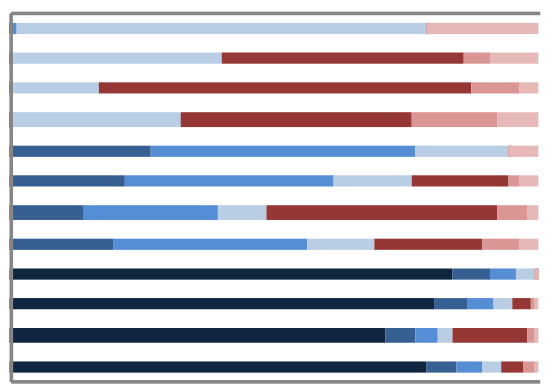

d) Terrestrial Eutrophication

$\begin{array}{llllll}0 \% & 20 \% & 40 \% & 60 \% & 80 \% & 100 \%\end{array}$

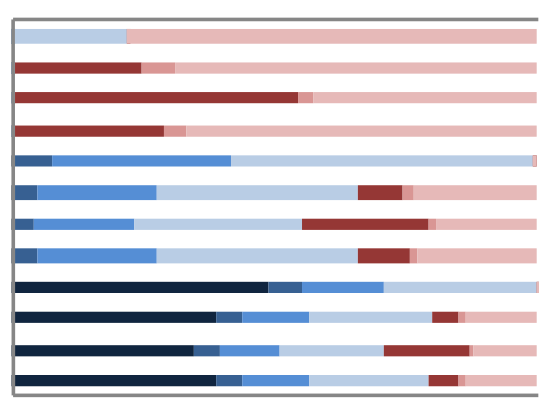

f) Ecotoxicity
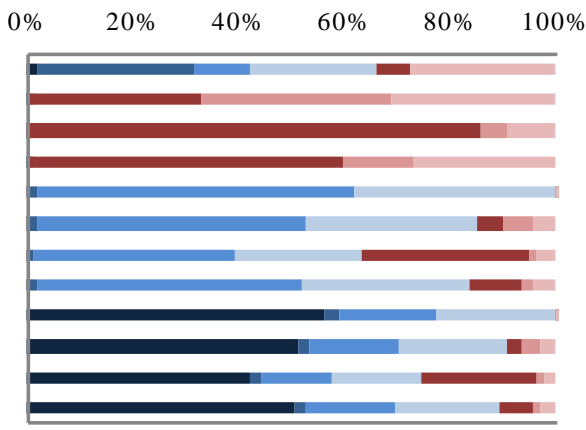

h) Ozone Depletion

Raw Material_PTA*

$\mathrm{IBA}^{* *}$

PX

PTA Raw Material EG

EtOH

EG

* The blue gradient is for PTA production whereas the red is for EG manufacturing.

${ }^{* * *}$ For fossil-based PTA, no IBA was produced. PX is directly processed from a series of petroleum refinery coproducts. Therefore, the IBA blocks for fossil PTA actually refers to impacts from petroleum refinery co-products.

294 Fig. 3. Unit process impacts for 12 different PET bottle production scenarios. 
295 Climate change impacts (Global Warming Potentials, GWPs) of forest residue-derived bottles is about 4.14

296 to $4.92 \mathrm{~kg} \mathrm{CO}_{2}$-equivalent per kg PET bottles. This results in $27 \%$ lower $\mathrm{CO}_{2}$-eq than those produced from

297 corn stover PTA bottles ( $\sim 5.49$ to $6.48 \mathrm{~kg} \mathrm{CO}_{2}$-eq/kg PET bottles) and $21 \%$ lower than those from fossil

298 PTA bottles ( 4.74 to $6.36 \mathrm{~kg} \mathrm{CO}_{2}$-eq $/ \mathrm{kg}$ PET bottles) on average. If no credits were taken into account,

299 however, forest residue PTA bottles would have higher GWPs than fossil PTA bottles. The processes that

300 contribute greatest to each of the scenario impacts are presented in Fig. 3a. Extraction of crop residues was

301 found to be a particularly impactful phase; specifically, the establishment of cornfields, together with the

302 harvesting and handling of corn stover, made raw material extraction a big emitter of greenhouse gases.

303 Another primary contributor of impact is the IBA production process in wood PTA scenarios. The process

304 involves several steps including pretreatment, enzymatic hydrolysis, and fermentation - where

305 polysaccharides are turned into fermentable sugars and then processed to IBA. Woody-biomass has a

306 higher lignin content than non-woody biomass. Lignin binds cellulose and hemicellulose together and

307 forms lignocellulose, which is highly recalcitrant to microbial and enzymatic digestion (Zhu and Pan,

308 2010). Hence, compared to other kinds of biomass (such as sugar, molasses and starch), a considerable

309 amount of extra energy is required to destruct lignocellulose in woody biomass (Hendriks and Zeeman,

310 2009; Mosier et al., 2005), leading to an overall higher environmental impact than petroleum-based PX

311 extraction processes. It is notable that switchgrass production yielded high impacts compared to that of

312 wheat straw and corn grain. However, since switchgrass has not yet been produced as a commercial crop,

313 the data uncertainty is relatively higher, which may potentially lead to its worse environmental profile (Hsu

314 et al., 2010; Spatari et al., 2005). Uncertainty about the estimated IBA process inputs is discussed in the

315 sensitivity analysis section.

317 Compared to GWP impacts, the results of the fossil fuel consumption category are more intuitive,

318 confirming that bio-PET bottles generally consume less fossil energy than fossil PET bottles (Fig. 2b).

319 Producing wood PTA bottles with displacement credits ( 8.10 to $10.41 \mathrm{MJ}$ surplus energy/kg PET bottles)

320 required even fewer fossil fuels (22\% and 9\% lower than the fossil PTA and corn stover PTA groups,

321 respectively). It is obvious that extracting petroleum-derived resources consumes a large amount of fossil 
322 energy. However, it is worth mentioning that the production of IBA is the leading consumer of fossil

323 energy in the production of woody biomass PTA, whereas feedstock extraction generated the largest share

324 for corn stover PTA. As mentioned previously, significant amounts of energy are required to destruct

325 lignocellulose to fermentable sugars and convert them to IBA. Also, compared to forest residues extraction,

326 the corn stover production stage is energy intensive (including corn farming and corn stover collection),

327 driven by fertilizer production, tillage and harvesting processes (e.g. grinding and drying) (Valipour, 2014;

328 Valipour, 2012; Valipour et al., 2015; Hsu et al., 2010; Luo et al., 2009).

330 The corn stover PTA group has the greatest acidification impact, followed by wood and fossil PTA groups

331 (Fig. 2c). Avoiding slash pile burning results in approximately $0.014 \mathrm{~kg} \mathrm{SO}_{2}$ equivalent $/ \mathrm{kg}$ bottles of

332 impact offsets for forest residue PTA bottles, but still results in 27\% higher acidification impact than their

333 fossil-based counterpart. Further, its clear that bio-based EGs on average release more acidifying emissions

334 than fossil-based EGs (Fig. 3c). Bio-chemical processing of IBA once again represented a large portion of

335 the acidification impacts for wood-PTA scenarios ( $30 \%)$, primarily due to use of processing chemicals

336 and combustion of fuels. Fig. 3c reveals that in the fossil-PTA + bio-EG scenarios the agricultural stages of

337 corn, switchgrass and wheat straw all released considerable amounts of acidifying compounds, resulting in

338 feedstock extraction being the decisive stage responsible for overall higher acidification impacts.

339 Specifically, switchgrass extraction took up more than half $(\sim 53 \%)$ of the total acidification impacts from

340 fossil-switchgrass bottles, primarily due to fertilizer production (Monte et al. 2009) and application (Fu et

341 al., 2003). For corn stover-PTA scenarios, corn stover production stage took the largest share with roughly

$34263 \%$ of overall impacts from PTA and EG. Other than fertilizing and harvesting operations, this could also

343 be explained by the impact allocation choices made between corn grains and corn stover (Williams et al.,

344 2009). Similarly, retrieving forest residues generated additional acidification impacts compared to fossil

345 feedstock ( $0.0096 \mathrm{~kg} \mathrm{SO}_{2}$-eq/kg bottles), due primarily to the fossil fuel combustion required by forestry

346 management, as forests need very limited fertilization (Spellman, 2011). 
348 For eutrophication impacts on terrestrial ecosystems, wood PTA bottles have a similar performance to 349 fossil PTA bottles. The corn stover PTA group, however, generated significantly higher eutrophying 350 emissions, equaling approximately 5 times the eutrophying impacts of those driven by fossil and wood 351 PTA groups on average. It was evident in Fig. 3d that retrieving crop biomass in general released more N352 nutrients to the soil ecosystem than fossil and forest residue extraction. For corn stover acquisition, 353 emissions come from two dominant impact drivers, namely fertilizer and hay production, with each 354 contributing to approximately $50 \%$ of the unit process impacts. Note that low-quality hay was used to 355 substitute corn stover as over-winter feed, and therefore the environmental burden brought by hay 356 processing needs is included. The only emissions documented for processing fertilizer and hay were $\mathrm{NH}_{3}$ 357 and $\mathrm{NO}_{\mathrm{x}}$, which were driven by $\mathrm{N}$-related physical input conversions, such as ammonia, urea, and 358 ammonium nitrate (Hsu et al., 2010). The eutrophication indicator chosen here, accumulated exceedance,

359 takes exactly $\mathrm{NH}_{3}$ and $\mathrm{NO}_{\mathrm{x}}$ to calculate overloaded $\mathrm{N}$ nutrients deposition (Seppälä et al., 2006). Hence, it 360 was expected that those two processes were eutrophication intensive. Fertilization may also explain the

361 large share of eutrophication impacts from producing corn grain, switchgrass and wheat straw in fossil PTA

362 + bio-EG bottle scenarios ( 46\%, 70\% and 44\%, respectively). In addition, switchgrass required more 363 bailing inputs, leading to extra emissions (Hsu et al., 2010). Producing IBA from wood residues was the 364 decisive factor for eutrophication impacts for forest residue bottles, mostly due to the N-based materials 365 applied in the bio-chemical conversion process. However, since forestry requires very limited fertilization 366 (Puettmann et al., 2012), the eutrophication impacts are trivial compared to corn stover PTA scenarios.

368 Human Health Particulate emissions are interpreted in kg PM2.5 equivalent per kg PET bottles, shown in

369 Fig. 2e. On average, forest residue PTA bottles with displacement credits have the lowest impacts ( -0.043

370 to -0.041 kg PM2.5-eq/kg PET bottles), but were comparable to other scenarios without avoided impacts 371 incorporated ( 0.0037 to $0.0059 \mathrm{~kg}$ PM2.5-eq $/ \mathrm{kg}$ PET bottles). While avoided particulate emissions from

372 slash pile burning accounts for most of the credits (Ganguly et al., 2014), this assumption could vary due to 373 differences on geographical areas, types of woody biomass, and forestry logistics scenarios. For this reason, 374 we address this potential variability in a sensitivity analysis. It was clear in Fig. 3e that if no avoided 
375 impacts are applied, particulate emissions become significant in the forest residue extraction phase as well

376 as the wood-IBA processing stage. Corn stover and wheat straw extraction impacts, on the other hand, are

377 primarily attributed to the grinding process and electricity usage. For switchgrass production, bailing during

378 the harvest operation is the primary contributor to impact, whereas for corn grains, fertilizer production,

379 tillage and irrigation processes are responsible for the majority of particulate emissions.

381 To evaluate the eco-toxicity potential, TRACI v2.1 uses the USEtox model which is based on the metric

382 'comparative toxic units' (CTUe) (Rosenbaum et al., 2008). Note that the USEtox model includes both

383 recommended and interim characterization factors, where the latter ones need to be used with caution

384 (Bare, 2011; Hauschild et al., 2011). To reduce uncertainty, GaBi only considers recommended factors

$385(\mathrm{GaBi}, 2014)$. The majority of eco-toxicity potential impacts are due to bio-EGs and bio-PTAs. Electricity

386 consumption and grinding processes are the most impact-intensive factors for corn stover PTA and wheat

387 straw EG, whereas the bailing process is responsible for most of the eco-toxicity impacts from switchgrass

388 EG. Corn grain EG bottles, on the other hand, gain their eco-toxicity mainly from pesticide and fertilizer

389 production. Finally, bio-PTAs production in 70\% bio-based bottles (i.e. wood PTA and corn stover PTA

390 paired with fossil EG) have extremely high eco-toxicity impacts due to wood IBA processing and corn

391 stover extraction, respectively.

393 With regard to smog effects, compared to corn stover and fossil counterparts, bio-PTA bottles have higher

394 emissions than fossil PTA bottles. Primary offsets come from the avoidance of slash pile burning, but Fig.

$3953 \mathrm{~g}$ shows that forest logistics remain the primary cause of smog generation, as the handling of bulky wood

396 logs and branches is energy intensive. Similarly, just as with eco-toxicity and human health particulates,

397 smog impacts increased greatly with the extraction of agricultural feedstocks due to the fuel combustion

398 from operating agricultural machinery (for tillage, grinding, drying and bailing). Energy consumption in

399 supplementary material production (fertilizer, pesticide and hay) contribute as well. These are also decisive

400 factors behind the high ozone depletions with the production of bio-based PTA bottles, whereas bio-EG

401 generated close to $100 \%$ ozone depletion impacts when paired with a fossil PTA. 
$403 \quad 3.2$ Sensitivity Analysis and Limitations

404

405 LCIA results for woody biomass-derived PET bottles (Scenario $5-8$ ) were found sensitive to several

406 factors. Sensitivity analysis results are presented as percentage changes of the initial credited Scenario 5

407 (Wood PTA + Fossil EG) impacts. Complete results can be found in SI.

408

409 Currently the U.S. national PET container recycling rate is about 30\% (NAPCOR, 2015). Therefore, figure

4104 explores the possibility of PET bottles being landfilled or burned for energy use by illustrating GWP

411 results for the 12 scenarios with and without carbon sequestration credits. It is obvious that if those credits

412 are excluded, partially/fully bio-based PET bottles (Scenario 2-12) would lose their advantage over fossil

413 PET bottles (Scenario 1).

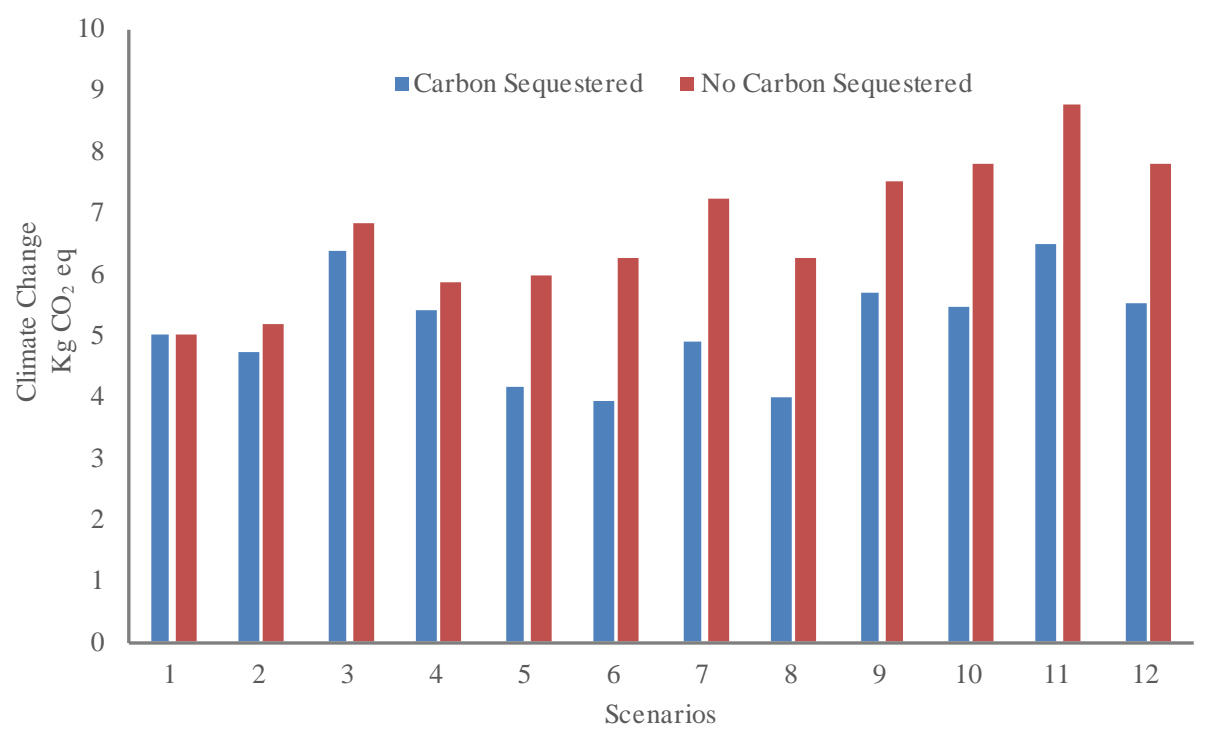

Fig. 4. Comparison of scenario GWP results (per kg PET bottles) with/without carbon sequestration credits. 
417 Table 2 addresses the uncertainty in paraxylene and IBA processing inputs, and assumptions of avoided

418 impacts from slash pile burning by altering the quantities of input values and assessing the change in

419 impacts. Apparently, variability in both slash pile burning and IBA impact estimates considerably influence

420 final results, but changes in PX processing impacts have relatively minimal influence on final results.

421 Climate change, acidification and smog were all vulnerable to modified assumptions of IBA production

422 inputs, with a 55\% reduction in IBA inputs (leaving only $45 \%$ of baseline IBA input values in the system)

423 leading to $16 \%, 12 \%$ and $6 \%$ decreases in the corresponding impacts of credited Scenario 5. Acidifying

424 emissions also decrease by $32 \%$ if $55 \%$ of the slash pile burning credits were removed. Particulate

425 emissions are also largely dependent on the avoided slash burn assumption, with a 55\% credit reduction

426 resulting in a $60 \%$ increase in fine particulate impacts. Smog would also have a dramatic increase of $73 \%$.

427 Collectively, such uncertainty could largely alter the conclusion of environmental rankings for fossil and

428 bio-PET bottles. Future studies should address data refinement issues in order to increase confidence in

429 relative results.

431 Table 2

432 Percentage changes of selected impacts of credited scenario 5 results introduced by changing input

433 quantities in different unit processes.

\begin{tabular}{lcccccccccc}
\hline & \multicolumn{3}{c}{ Upgrading IBA to PX (\%) } & \multicolumn{3}{c}{ Isobutanol Process (\%) } & \multicolumn{3}{c}{ Slash Pile Burning (\%) } \\
\cline { 2 - 9 } $\begin{array}{l}\text { \% of Baseline } \\
\text { Input Values }\end{array}$ & $45 \%^{*}$ & $70 \%$ & $135 \%$ & $45 \%^{*}$ & $70 \%$ & $135 \%$ & $45 \%^{*}$ & $70 \%$ & $135 \%$ \\
\hline Climate Change & -2.3 & -1.3 & +1.4 & -16.1 & -8.8 & +10.2 & +3.3 & +1.8 & -2.1 \\
Acidification & -0.3 & -0.2 & +0.2 & -11.8 & -6.4 & +2.1 & +32.3 & +17.6 & -20.6 \\
Particulates & -0.0 & -0.0 & +0.0 & -0.4 & -0.2 & +0.1 & +59.7 & +32.6 & -38.0 \\
Smog & -0.6 & -0.3 & +0.4 & -6.3 & -3.5 & +1.2 & +73.3 & +40.0 & -46.6 \\
\hline
\end{tabular}

$434 \quad$ "Discussion provided in text.

435 We compared our results with relevant LCIs for validation. Adom et al. (Adom et al. 2014) studied the life

436 cycle greenhouse gas emissions of IBA produced from corn stover, and revealed a $2.7 \mathrm{~kg} \mathrm{CO}_{2} \mathrm{e} / \mathrm{kg} \mathrm{IBA}$

437 impact, which is very close to the number in our study using wood residues (2.70 $\mathrm{kg} \mathrm{CO}_{2} \mathrm{e} / \mathrm{kg} \mathrm{IBA} \mathrm{impact).}$ 
438 Akanuma et al. 2014 documented life cycle impacts from different 100\% bio-based PET production

439 scenarios and they found a GHG emission of $6.81 \mathrm{~kg} \mathrm{CO} 2 \mathrm{e} / \mathrm{kg}$ PET for their butanol pathway, which is

440 comparable to this study's forest residue PTA + corn EG PET bottle emissions $\left(6.23 \mathrm{~kg} \mathrm{CO}_{2} \mathrm{e} / \mathrm{kg}\right.$ PET

441 bottles, without carbon sequestration credits), but lower than those from the corn-stover PTA + corn EG

442 scenario (7.79 $\mathrm{kg} \mathrm{CO}_{2} \mathrm{e} / \mathrm{kg}$ PET bottles without carbon sequestration credits).

443 A limitation of the study lies in the data availability of the fossil fuel scenarios. LCI information about

444 fossil PTA and EG production specific to U.S. conditions are available in $\mathrm{GaBi}$, but only in aggregated

445 format. Therefore, unit process data was estimated based on the percentage share each unit stage takes,

446 which was calculated based on corresponding data from Ecoinvent (Weidema et al., 2013). In such a case,

447 the comparative results of biomass unit processes and fossil unit processes must be considered with

448 caution.

\section{Conclusions and Recommendations}

452 According to the aforementioned outcomes, mixed results were found across impact categories when

453 comparing the environmental performances of partially and fully bio-based PET bottles versus fossil-based

454 ones. In most categories, with avoided impact credits considered, forest residues had a better or comparable

455 environmental profile to corn stover when used as feedstock for bio-PET bottles. The conclusion is subject

456 to uncertainty, where variability in avoided burdens could alter the conclusion of environmental rankings

457 for fossil and bio-PET bottles. Moreover, a summary of unit process impacts implies that biomass

458 feedstock extraction and pre-processing are likely more emission-intensive than corresponding fossil

459 refinery processes, either due to the extra energy required for agricultural operations, or because of the

460 production and application of required chemicals. As a result, future research should focus on: 1)

461 improving the availability and reliability of LCI data; 2) developing more detailed avoided impact

462 scenarios; 3 ) optimizing biorefinery processes; 4) determining a sustainable residue collection rate (Andrew, 
463 2006); 5) incorporating economic analyses to deliver a more robust and comprehensive sustainable

464 portfolio of PET bottle bio-refineries.

465

466 Acknowledgment The authors acknowledge the technical contributions of Allan Gao, Tom Spink, Shulin Chin, Gevan

467 Marrs, and other members of the Northwest Advanced Renewables Alliance (NARA), who provided valuable feedback

468 and supplied necessary data required for this study. Special thanks to Scott Geleynse, Xiao Zhang and Manuel Garcia-

469 Perez for their help with unit input/out data for bio-paraxylene. The authors also acknowledge the financial support of

470 the Agriculture and Food Research Initiative Competitive Grant No. 2011-68005-30416 from the USDA National

471 Institute of Food and Agriculture.

472

473 Reference

474 Adom, F., Dunn, J.B., Han, J., Sather, N., 2014. Life-Cycle Fossil Energy Consumption and Greenhouse

475 Gas Emissions of Bioderived Chemicals and Their Conventional Counterparts. Environ. Sci.

476 Technol. 48, 14624-14631. doi:10.1021/es503766e

477 Akanuma, Y., Selke, S.E.M., Auras, R., 2014. A preliminary LCA case study: comparison of different

478 pathways to produce purified terephthalic acid suitable for synthesis of $100 \%$ bio-based PET. The

479 International Journal of Life Cycle Assessment 19, 1238-1246. doi:10.1007/s11367-014-0725-2

480 Andrews, S.S., 2006. Crop residue removal for biomass energy production: Effects on soils and

481 recommendations. US Department of Agriculture-Natural Resource Conservation Service,

482 http://soils. usda. gov/sqi/files/AgForum_Residue_White_Paper. pdf (15 November 2012).

483 Bare, J., 2011. TRACI 2.0: the tool for the reduction and assessment of chemical and other environmental 484 impacts 2.0. Clean Technol Environ 13:687-696.

485 Bare, J., Young, D., QAM, S., Hopton, M., Chief S.A.B., 2012. Tool for the Reduction and Assessment of 486 Chemical and other Environmental Impacts (TRACI) 
Bergeron, C., Carrier, D.J., Ramaswamy, S., 2012. Biorefinery co-products: phytochemicals, primary metabolites and value-added biomass processing. John Wiley \& Sons

Cherubini, F., 2010. The biorefinery concept: using biomass instead of oil for producing energy and chemicals. Energ Convers Manage 51:1412-1421

Coca-Cola Bottling Co. CONSOLIDATED (CCBCC). Our Heritage.

Curran, M.A., 1996. Environmental life-cycle assessment. Int J Life Cycle Ass 1:179-179

De Fraiture, C., Giordano, M., Liao, Y., 2008. Biofuels and implications for agricultural water use: blue impacts of green energy. Water Policy 10:67

Fargione, J., Hill, J., Tilman, D., Polasky, S., Hawthorne, P., 2008. Land clearing and the biofuel carbon debt. Science 319:1235-1238

Feldman, R.M.R., Gunawardena, U., Urano, J., Meinhold, P., Aristidou, A.A., Dundon, C.A., Smith, C., 2011. Yeast organism producing isobutanol at a high yield. U.S. Patent 8455239, issued 13 September, 2011.

501 Fernando, S., Adhikari, S., Chandrapal, C., Murali, N., 2006. Biorefineries: current status, challenges, and $502 \quad$ future direction. Energ Fuel 20:1727-1737.

503 Finnveden, G., Hauschild, M.Z., Ekvall, T., Guinée, J., Heijungs, R., Hellweg, S., Koehler, A., Pennington,

504 D., Suh, S., 2009. Recent developments in life cycle assessment. Journal of environmental management 91, 1-21.

506 Fu, G.Z., Chan, A.W., Minns, D.E., 2003. Life cycle assessment of bio-ethanol derived from cellulose. Int J Life Cycle Ass 8:137-141

508 GaBi LCA Software, PE International, 2014. www.gabi-software.com/america/index/ (accessed 509 2016.03.01) 
510 GaBi Software USEtox, 2014. http://www.gabi-software.com/america/support/gabi/gabi-lcia-

$511 \quad$ documentation/usetox/ (accessed 2016.03.01)

512 Ganguly, I., Eastin, I., Bowers, T., Huisenga, M., Pierobon, F., 2014. Environmental assessments of woody 513 biomass based jet-fuel. CINTRAFOR News 3-10.

514 Gironi, F., Piemonte, V., 2011. Life cycle assessment of polylactic acid and polyethylene terephthalate 515 bottles for drinking water. Environ Prog Sust Energ 30:459-468.

516 Guinée, J.B., 2002. Handbook on life cycle assessment operational guide to the ISO standards. Int J Life $517 \quad$ Cycle Ass 7:311-313

518 Harada, M., Ohya, T., Iida, K., Hayashi, H., Hirano, K., Fukuda, H., 2007. Increased impact strength of 519 biodegradable poly (lactic acid)/poly (butylene succinate) blend composites by using isocyanate as a 520 reactive processing agent. J Appl Polym Sci 106:1813-1820.

521 Hatti-Kaul, R., 2010. Biorefineries- A Path to Sustainability? doi: 10.2135/cropsci2009.10.0563

522 Hauschild, M., Goedkoop, M., Guinee, J., Heijungs, R., Huijbregts, M., Jolliet, O., Margni, M., De

523 Schryver, A., 2011. JRC Publications Repository: Recommendations for Life Cycle Impact

524 Assessment in the European context - based on existing environmental impact assessment models

525 and factors (International Reference Life Cycle Data System - ILCD handbook). Institute for

526 Environment and Sustainability. doi: 10.2788/33030

527 Hendriks, A., Zeeman, G., 2009. Pretreatments to enhance the digestibility of lignocellulosic biomass.

$528 \quad$ Bioresource Technol 100:10-18

529 Hsu, D.D., Inman, D., Heath, G.A., Wolfrum, E.J., Mann, M.K., Aden, A., 2010. Life cycle environmental 530 impacts of selected US ethanol production and use pathways in 2022. Environ Sci \& Technol

$531 \quad 44: 5289-5297$

532 International Organization for Standardization, 2006. Environmental Management: Life Cycle Assessment: $533 \quad$ Principles and Framework. ISO 
534 Jamshidian, M., Tehrany, E.A., Imran, M., Jacquot, M., Desobry, S., 2010. Poly-Lactic Acid: Production, 535 Applications, Nanocomposites, and Release Studies. Compr Rev Food Sci F 9:552-571

536 doi:10.1111/j.1541-4337.2010.00126.x

537 Jungmeier, G., Werner F., Jarnehammar A., Hohenthal C., Richter, K., 2002. Allocation in LCA of Wood538 based Products - Experiences of Cost Action E9, Part II. Examples. Int J LCA 7(6): 369-375.

539 Kamm, B., Kamm, M., Gruber, P.R., Kromus, S., 2008. Biorefinery Systems - An Overview. In:

540 Biorefineries-Industrial Processes and Products. Wiley-VCH Verlag GmbH, pp 1-40.

$541 \quad$ doi:10.1002/9783527619849.ch1

542 Kelloway, A., Daoutidis, P., 2013. Process synthesis of biorefineries: optimization of biomass conversion 543 to fuels and chemicals. Ind Eng Chem Res 53:5261-5273.

544 Komly, C.E., Azzaro-Pantel, C., Hubert, A., Pibouleau, L., Archambault, V., 2012. Multiobjective waste 545 management optimization strategy coupling life cycle assessment and genetic algorithms:

546 Application to PET bottles. Resour Conserv Recy 69:66-81.

547 Koncept Analytics, 2013. Global PET (Resin) Market Report - 2012 Edition.

548 Kumar, R., Singh, S., Singh, O.V., 2008. Bioconversion of lignocellulosic biomass: biochemical and 549 molecular perspectives. J Ind Microbiol Biot 35:377-391

550 Leu, S.Y., Zhu, J., Gleisner, R., Sessions, J., Marrs, G., 2013. Robust enzymatic saccharification of a 551 Douglas-fir forest harvest residue by SPORL. Biomass Bioenerg 59:393-401.

552 Lipinsky, E.S., 1981. Chemicals from biomass: petrochemical substitution options. Science 212:1465$553 \quad 1471$.

554 Luo, L., van der Voet, E., Huppes, G., 2009. An energy analysis of ethanol from cellulosic feedstock-corn $555 \quad$ stover. Renew Sust Energ Rev 13:2003-2011

556 Melillo, J.M., Reilly, J.M., Kicklighter, D.W., Gurgel, A.C., Cronin, T.W., Paltsev, S., Felzer, B.S., Wang, 557 X., Sokolov, A.P., Schlosser, C.A., 2009. Indirect emissions from biofuels: how important? Science $558 \quad 326: 1397-1399$ 
559 Monti, A., Fazio, S., Venturi, G., 2009. Cradle-to-farm gate life cycle assessment in perennial energy crops.

$560 \quad$ Eur J Agron 31:77-84. doi: http://dx.doi.org/10.1016/j.eja.2009.04.001

561 Mosier, N., Wyman, C., Dale, B., Elander, R., Lee, Y., Holtzapple, M., Ladisch, M., 2005. Features of

562 promising technologies for pretreatment of lignocellulosic biomass. Bioresource Technol 96:673-

$563 \quad 686$

564 NAPCOR, 2015. Report on Postconsumer PET Container Recycling Activity in 2014.

565 NAPCOR, 2010. PET Basics. In: NAPCOR. http://www.napcor.com/pdf/v4-

566 11_NAPCOR_PET_Interactive.pdf. (accessed 2016.03.01)

567 Narayan, R., 2011. Carbon footprint of bioplastics using biocarbon content analysis and life-cycle

$568 \quad$ assessment. MRS bulletin 36:716-721

569 National Renewable Energy Laboratory (NREL), 2012. U.S. Life Cycle Inventory Database.

$570 \quad$ https://www.lcacommons.gov/nrel/search. (accessed 2016.03.01)

571 Nelson, P., Hood, E., Powell, R., 2011. The Bioeconomy: A New Era of Products Derived from Renewable

572 Plant-Based Feedstocks. In: Plant Biomass Conversion. John Wiley \& Sons, Inc., pp 1-20

573 Pawelzik, P., Carus, M., Hotchkiss, J., Narayan, R., Selke, S., Wellisch, M., Weiss, M., Wicke, B., Patel,

574 M., 2013. Critical aspects in the life cycle assessment (LCA) of bio-based materials-Reviewing

575 methodologies and deriving recommendations. Resour Conserv Recy 73:211-228

576 PE INTERNATIONAL AG., 2014. Process data set: Biopolyethylene terephthalate granulate (PET) via

577 terepht. acid + EG (corn); partially biobased via terephthalic acid and ethylene glycol from

578 bioethylene based on corn; single route, at plant; PET bottle grade, Ethylene glycol biobased and

579 terephthalic acid fossil based; $20 \%$ biogenic and $80 \%$ fossil share based on total carbon amount (en).

580 http://gabi-documentation-2014.gabi-software.com/xml-data/processes/b8c7e89d-5f0c-4bc1-90d8-

$581 \quad 84 \mathrm{c} 12 \mathrm{~b} 6 \mathrm{c} 4 \mathrm{~d} 2 \mathrm{e} . \mathrm{xml}$. (accessed 2016.03.01)

582 Perlack, R., Stokes, B., Eaton, L., Turnhollow, A., 2011. US Billion-ton Update: Biomass Supply for a

583 Bioenergy and Bioproducts Industry. The US Department of Energy: Oak Ridge, TN 227. 
584 Peters, M., Taylor, J.D., Jenni, M., Manzer, L.E., Henton, D.E., 2011. Integrated process to selectively convert renewable isobutanol to p-xylene. Gevo Inc. U.S. Patent Application 12/899285, filed October 6, 2010.

Pimentel, D., Marklein, A., Toth, M.A., Karpoff, M., Paul, G.S., McCormack, R., Kyriazis, J., Krueger, T., 2008. Biofuel impacts on world food supply: use of fossil fuel, land and water resources. Energies $1: 41-78$

PlasticsEurope, 2013. http://www.plasticseurope.org/ (accessed 2016.03.04)

591 Puettmann, M., Oneil, E., Milota, M., Johnson, L., 2012. Cradle to Gate Life Cycle Assessment of

Rebitzer, G., Ekvall, T., Frischknecht, R., Hunkeler, D., Norris, G., Rydberg, T., Schmidt, W.P., Suh, S., Weidema, B.P., Pennington, D.W., 2004. Life cycle assessment: Part 1: Framework, goal and scope

Repo, A., Känkänen, R., Tuovinen, J.P., Antikainen, R., Tuomi, M., Vanhala, P., Liski, J., 2012. Forest bioenergy climate impact can be improved by allocating forest residue removal. GCB Bioenergy

Roberts, K.G., Gloy, B.A., Joseph, S., Scott, N.R., Lehmann, J., 2009. Life cycle assessment of biochar systems: Estimating the energetic, economic, and climate change potential. Environ Sci \& Technol

604 Rosenbaum, R.K., Bachmann, T.M., Gold, L.S., Huijbregts, M.A., Jolliet, O., Juraske, R., Koehler, A., 605 Larsen, H.F., MacLeod, M., Margni, M., 2008. USEtox - the UNEP-SETAC toxicity model:

606 recommended characterisation factors for human toxicity and freshwater ecotoxicity in life cycle 607 impact assessment. The International Journal of Life Cycle Assessment 13, 532-546. 
608 Scharathow, R., 2012. Driving the evolution of plastics - bioplastics markets and framework. http://www.plastice.org/fileadmin/files/8_Roland_Scharathow.pdf. (accessed 2016.03.01)

610 Schut, J.H., 2012. The Race to 100\% Bio PET. Plastics Engineering Blog.

611 http://plasticsengineeringblog.com/2012/08/13/the-race-to-100-bio-pet/ (accessed 2016.03.01)

612 Seppälä, J., Posch, M., Johansson, M., Hettelingh, J.P., 2006. Country-dependent Characterisation Factors

613 for Acidification and Terrestrial Eutrophication Based on Accumulated Exceedance as an Impact

614 Category Indicator (14 pp). Int J Life Cycle Ass 11:403-416. doi:10.1065/lca2005.06.215

615 Shen, L., Nieuwlaar, E., Worrell, E., Patel, M.K., 2011. Life cycle energy and GHG emissions of PET

616 recycling: change-oriented effects. The International Journal of Life Cycle Assessment 16, $522-536$.

617 Shen, L., Worrell, E., Patel, M.K., 2012. Comparing life cycle energy and GHG emissions of bio-based 618 PET, recycled PET, PLA, and man-made cellulosics. Biofuel Bioprod Bior 6:625-639.

619 Sims, R.E., Mabee, W., Saddler, J.N., Taylor, M., 2010. An overview of second generation biofuel 620 technologies. Bioresource Technol 101:1570-1580

621 Smeets, E.M., Faaij, A.P., 2007. Bioenergy potentials from forestry in 2050. Climatic Change 81:353-390.

622 Spatari, S., Zhang, Y., MacLean, H.L., 2005. Life cycle assessment of switchgrass-and corn stover-derived 623 ethanol-fueled automobiles. Environ Sci \& Technol 39:9750-9758

624 Spellman, F., 2011. Bioenergy. In: Forest-Based Biomass Energy: Concepts and Applications. CRC Press

625 Stephen, J.D., Mabee, W.E., Saddler, J.N., 2012. Will second-generation ethanol be able to compete with 626 first-generation ethanol? Opportunities for cost reduction. Biofuel Bioprod Bior 6:159-176

627 Stevens, C., Verhé, R., 2004. Renewable bioresources: scope and modification for non-food applications. $628 \quad$ John Wiley \& Sons

629 Tabone, M.D., Cregg, J.J., Beckman, E.J., Landis, A.E., 2010. Sustainability metrics: life cycle assessment $630 \quad$ and green design in polymers. Environ Sci \& Technol 44:8264-8269 
631 Tao, L., Tan, E.C.D., McCormick, R., Zhang, M., Aden, A., He, X., Zigler, B.T., 2014. Techno-economic 632 analysis and life-cycle assessment of cellulosic isobutanol and comparison with cellulosic ethanol 633 and n-butanol. Biofuels Bioprod Bior 8:30-48 doi:10.1002/bbb.1431

634 Tillman, A.M., Ekvall, T., Baumann, H., Rydberg, T., 1994. Choice of system boundaries in life cycle 635 assessment. J Clean Prod 2:21-29

636 U.S. Energy Information Administration (EIA), 2013. Energy sources have changed throughout the history 637 of the United States. Today in Energy. http://www.eia.gov/todayinenergy/detail.cfm?id=11951.

$638 \quad$ (accessed 2016.03.01)

639 Valipour, M., 2015a. A comprehensive study on irrigation management in Asia and Oceania. Archives of $640 \quad$ Agronomy and Soil Science 61, 1247-1271.

641 Valipour, M., 2015b. Future of agricultural water management in Africa. Archives of Agronomy and Soil $642 \quad$ Science 61, 907-927.

643 Valipour, M., 2014. Drainage, waterlogging, and salinity. Archives of Agronomy and Soil Science 60, $644 \quad 1625-1640$.

645 Valipour, M., 2012. Sprinkle and trickle irrigation system design using tapered pipes for pressure loss 646 adjusting. Journal of Agricultural Science 4, 125.

647 Valipour, M., Sefidkouhi, M.A.G., Eslamian, S., 2015. Surface irrigation simulation models: a review. 648 International Journal of Hydrology Science and Technology 5, 51-70.

649 Vink, E.T., Rabago, K.R., Glassner, D.A., Gruber, P.R., 2003. Applications of life cycle assessment to $650 \quad$ NatureWorks ${ }^{\mathrm{TM}}$ polylactide (PLA) production. Polym Degrad Stabil 80:403-419.

651 Vivekanandhan, S., Mohanty, A., Misra, M., Zarrinbakhsh, N., 2013. Coproducts of Biofuel Industries in 652 Value-Added Biomaterials Uses: A Move Towards a Sustainable Bioeconomy. INTECH Open 653 Access Publisher 
654 Wang, M., Huo, H., Arora, S., 2011. Methods of dealing with co-products of biofuels in life-cycle analysis 655 and consequent results within the U.S. context. Energ Policy 39:5726-5736

656 doi:http://dx.doi.org/10.1016/j.enpol.2010.03.052

657 Weidema, B.P.; Bauer, Ch.; Hischier, R.; Mutel, Ch.; Nemecek, T.; Reinhard, J.; Vadenbo, C.O.; Wernet,

658 G., 2013. The ecoinvent database: Overview and methodology, Data quality guideline for the

659 ecoinvent database version 3, www.ecoinvent.org

660 Williams, P.R., Inman, D., Aden, A., Heath, G.A., 2009 Environmental and sustainability factors associated 661 with next-generation biofuels in the US: what do we really know? Environ Sci \& Technol 43:4763-

$662 \quad 4775$

663 Zaimes, G., Borkowski, M., Khanna, V., 2013. Life-Cycle Environmental Impacts of Biofuels and Co-

664 products. In: Biofuel Technologies. Springer, pp 471-499

665 Zelm, R., 2009. ReCiPe 2008, A life cycle impact assessment method which comprises harmonised

666 category indicators at the midpoint and the endpoint level, Report I: characterisation. Den Haag, The

$667 \quad$ Netherlands

668 Zhang, H., Wen, Z.G., 2014. The consumption and recycling collection system of PET bottles: a case study 669 of Beijing, China. Waste Manage 34:987-998.

670 Zhu, J., Pan, X., 2010. Woody biomass pretreatment for cellulosic ethanol production: technology and 671 energy consumption evaluation. Bioresource Technol 101:4992-5002 


\section{Figure and Table Captions with Size Suggestions}

673 Fig. 1. Cradle-to-Gate system boundary for 100\% bio-based PET bottles

674 Preferred magnification factor: 1.5 column

675 Fig. 2. Life Cycle Impact Analysis results for 12 PET bottle production scenarios (per kg PET bottles).

676 Preferred magnification factor: Double column (full width)

677 Fig. 3. Unit process impacts for 12 different PET bottle production scenarios.

678 Preferred magnification factor: Double column (full width)

679 Fig. 4. Comparison of scenario GWP results (per kg PET bottles) with/without carbon sequestration credits.

680 Preferred magnification factor: 1.5 column

681 Table 1 Scenarios of Fossil-based and Bio-based PET Bottles.

682 Table 2 Percentage changes of selected impacts of credited scenario 5 results introduced by changing input 683 quantities in different unit processes. 


\section{Figure}

!

.

\section{Pretreatment}

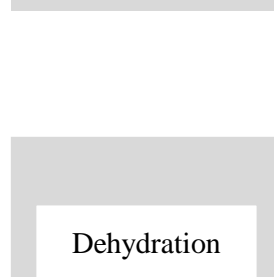

\section{Dehydration}

Oligomerization

Enzymatic

Hydrolysis

Fermentation

Paraxylene

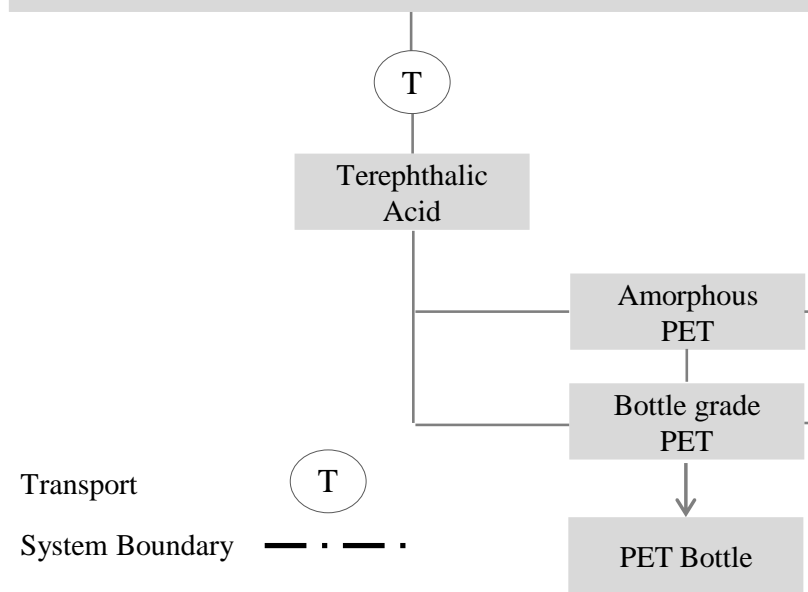

Dehydrocyclization

Isobutanol

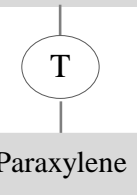


Figure

2 Fossil_Corn

3 Fossil_Switch

4 Fossil_Wheat

5 Wood_Fossil

6 Wood Corn

7 Wood_Switch

8 Wood Wheat

9 Stover Fossil

10 Stover_Corn

11 Stover_Switch

12 Stover_Wheat

1 Fossil_Fossil

2 Fossil_Corn

3 Fossil_Switch

4 Fossil_Wheat

5 Wood Fossil

6 Wood_Corn

7 Wood Switch

8 Wood Wheat

9 Stover_Fossil

10 Stover_Corn

11 Stover_Switch

12 Stover_Wheat

a) Climate Change

$\begin{array}{llllll}0 \% & 20 \% & 40 \% & 60 \% & 80 \% & 100 \%\end{array}$

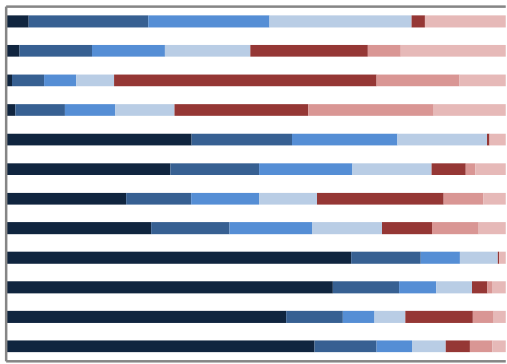

c) Acidification

$\begin{array}{llllll}0 \% & 20 \% & 40 \% & 60 \% & 80 \% & 100 \%\end{array}$

1 Fossil_Fossil

2 Fossil_Corn

3 Fossil_Switch

4 Fossil_Wheat

5 Wood_Fossil

6 Wood_Corn

7 Wood Switch

8 Wood Wheat

9 Stover_Fossil

10 Stover_Corn

11 Stover_Switch

12 Stover_Wheat

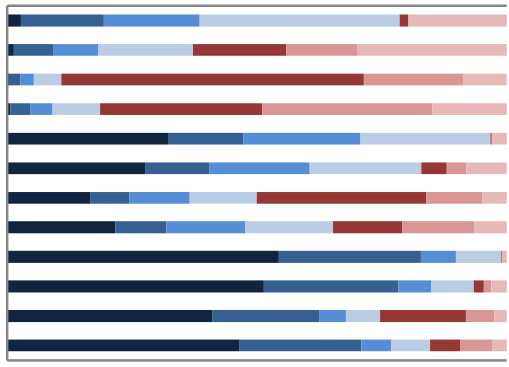

e) Human Health Particulates
$0 \%$
$20 \%$
$40 \%$
$60 \%$
$80 \%$
$100 \%$

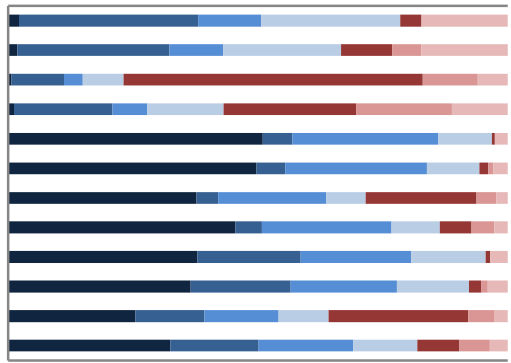

g) $\mathrm{Smog}$

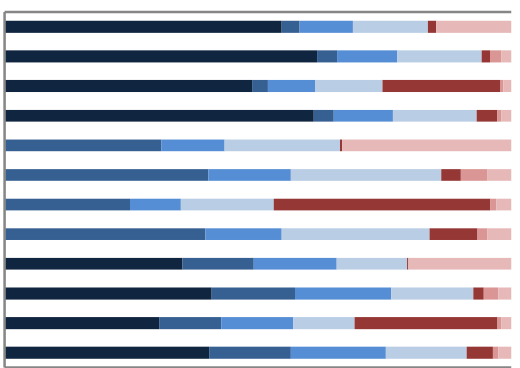

b) Fossil Fuel Depletion

$0 \% \quad 20 \% \quad 40 \% \quad 60 \% \quad 80 \%$

$100 \%$

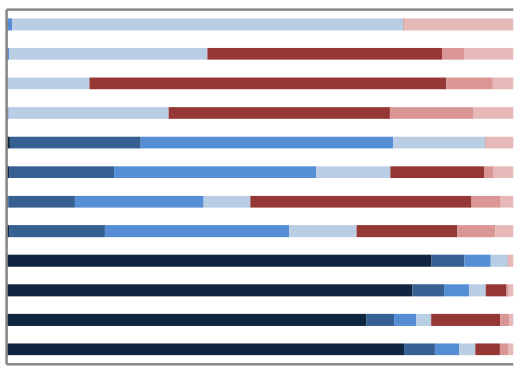

d) Terrestrial Eutrophication
$0 \%$
$20 \%$
$40 \%$
$60 \%$
$80 \%$
$100 \%$

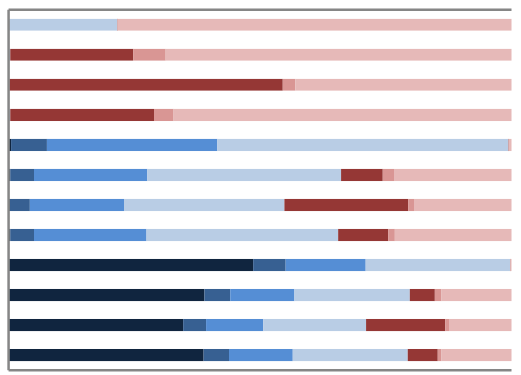

f) Ecotoxicity
$0 \%$
$20 \%$
$40 \%$
$60 \%$
$80 \%$
$100 \%$

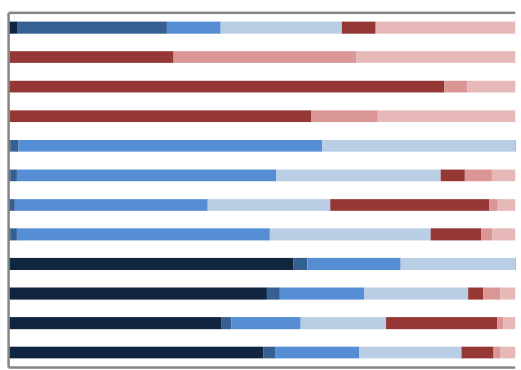

h) Ozone Depletion

\section{Raw Material_PTA* $\quad$ IBA $^{* *} \quad$ PX $\quad$ PTA $\quad$ Raw Material_EG \\ EtOH EG}

* The blue gradient is for PTA production whereas the red is for EG manufacturing.

${ }^{* *}$ For fossil-based PTA, no IBA was produced. PX is directly processed from a series of petroleum refinery coproducts. Therefore, the IBA blocks for fossil PTA actually refers to impacts from petroleum refinery co-products. 


\section{Figure}

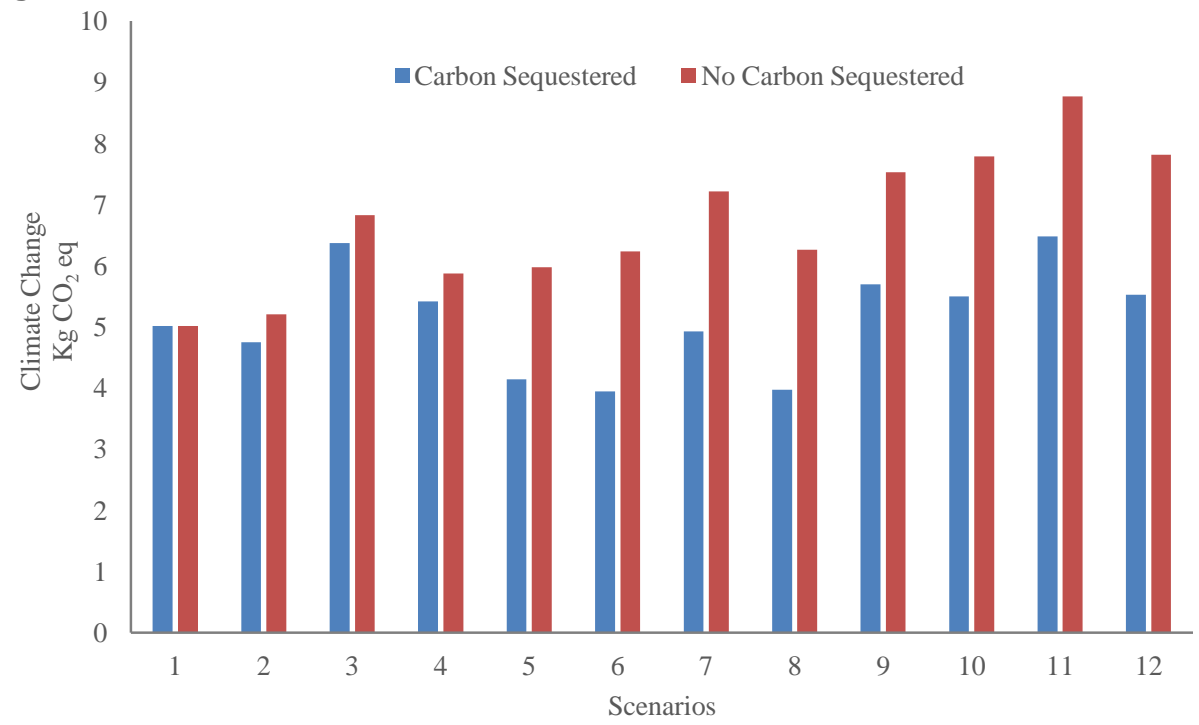


Table 1

Scenarios of Fossil-based and Bio-based PET Bottles.

\begin{tabular}{llll|llll}
\hline Scenario & $\begin{array}{l}\text { Feedstock } \\
\text { of PTA }\end{array}$ & $\begin{array}{l}\text { Feedstock } \\
\text { of EG }\end{array}$ & $\begin{array}{l}\% \text { of } \\
\text { Biomass }\end{array}$ & $\begin{array}{l}\text { Scenario } \\
\text { Feedstock } \\
\text { of PTA }\end{array}$ & $\begin{array}{l}\text { Feedstock } \\
\text { of EG }\end{array}$ & $\begin{array}{l}\% \text { of } \\
\text { Biomass }\end{array}$ \\
\hline $1^{\text {a }}$ & Fossil & Fossil & 0 & 7 & Wood & Switchgrass & 100 \\
2 & Fossil & Corn & 30 & 8 & Wood & Wheat Straw & 100 \\
3 & Fossil & Switchgrass & 30 & 9 & Corn Stover & Fossil & 70 \\
4 & Fossil & Wheat Straw & 30 & 10 & Corn Stover & Corn & 100 \\
5 & Wood & Fossil & 70 & 11 & Corn Stover & Switchgrass & 100 \\
6 & Wood & Corn & 100 & 12 & Corn Stover & Wheat Straw & 100 \\
\hline
\end{tabular}

${ }^{\mathrm{a}}$ Baseline scenario. 
Table 2

Percentage changes of selected impacts of credited scenario 5 results introduced by changing input quantities in different unit processes.

\begin{tabular}{lccccccccc}
\hline & \multicolumn{3}{c}{ Upgrading IBA to PX (\%) } & \multicolumn{2}{c}{ Isobutanol Process (\%) } & \multicolumn{3}{c}{ Slash Pile Burning (\%) } \\
\cline { 2 - 9 } $\begin{array}{l}\text { \% of Baseline } \\
\text { Input Values }\end{array}$ & $45 \%$ & $70 \%$ & $135 \%$ & $45 \%$ & $70 \%$ & $135 \%$ & $45 \%$ & $70 \%$ & $135 \%$ \\
\hline Climate Change & -2.3 & -1.3 & +1.4 & -16.1 & -8.8 & +10.2 & +3.3 & +1.8 & -2.1 \\
Acidification & -0.3 & -0.2 & +0.2 & -11.8 & -6.4 & +2.1 & +32.3 & +17.6 & -20.6 \\
Particulates & -0.0 & -0.0 & +0.0 & -0.4 & -0.2 & +0.1 & +59.7 & +32.6 & -38.0 \\
Smog & -0.6 & -0.3 & +0.4 & -6.3 & -3.5 & +1.2 & +73.3 & +40.0 & -46.6 \\
\hline
\end{tabular}

